\title{
Benefits and Risks in Dynamic Manufacturing Networks
}

\author{
Ourania Markaki, Panagiotis Kokkinakos, Dimitrios Panopoulos, \\ Sotirios Koussouris, and Dimitrios Askounis

\begin{abstract}
Greek Interoperability Center, Decision Support Systems Laboratory, School of Electrical and Computer Engineering, National Technical University of Athens, Greece \{omarkaki, pkokkinakos, dpano, skous, askous\} @epu.ntua.gr
\end{abstract}

\begin{abstract}
More and more manufacturing enterprises realize that, by operating as single enterprises in traditional supply chains, they cannot cope with the challenges of the modern demanding environment, and that they need to adopt new and innovative strategies in order to remain competitive. The establishment of Dynamic Manufacturing Networks (DMNs) brings together various innovations, such as just-in-time delivery, flexible manufacturing, organizational streamlining, and total quality, and emerges therefore as an advanced reaction of collaborating enterprises to the constantly changing business environment and its characteristics. This paper aims to expose the benefits and risks involved in such networks, and create thereby the foundation for elaborating further on the key factors that could be utilized for attracting organizations and enterprises into embracing the vision of DMNs, supporting thus not only industrial organizations and practitioners interested in implementing such solutions, but also scholars and researchers who study these new forms of business.
\end{abstract}

Keywords: Dynamic Manufacturing Network, DMN, Benefits, Risks.

\section{Introduction}

Survival and growth of enterprises in the intense competitive and innovation-driven environment of the $21^{\text {st }}$ century are beyond any doubt determined by their ability to continuously improve their performance, skills and the complete set of operations, both internally and externally. Today's manufacturing landscape is characterized by dramatic and often unanticipated changes in demand, rapid change and increased use of technology, short product lifecycles, time compression, complexity and fierce global competition [1]. In this competitive environment, the manufacturing enterprise must develop and implement new and innovative strategies in order to succeed.

In the light of remaining flexible and competitive, the manufacturing enterprise witnessed during the last decades a progression of initiatives targeting the improvement of its operation. In the 1980s, many companies focused on Total Quality Management (TQM) [2]. Later, they implemented factory automation in various "islands" on the factory floor and afterwards they focused on how to integrate these "islands of automation" [3]. Flexibility became a key component, while agility took the former concept one step further by embodying as well the ability to respond to unanticipated change. The next step of improvement was to extend beyond the factory, to suppliers.

C. Emmanouilidis, M. Taisch, D. Kiritsis (Eds.): APMS 2012, Part II, IFIP AICT 398, pp. 438-445, 2013.

(C) IFIP International Federation for Information Processing 2013 
Supply chain management has had a similar progression over the years in the interest of reducing costs, improving quality and shortening delivery cycles [4]. In the 1980s, improvements were focused on solving specific quality problems, and shifting inventory risk from the large company to the supplier base was the primary strategy applied during this period, while the early 1990s were characterized by crossfunctional teams of primes and suppliers working to improve process capability and implement compatible systems interfaces with a limited contribution of suppliers' engineering knowledge to new product development.

Nowadays, competition and other pressing market situations, such as fluctuating demand or market saturation have greatly intensified to the point where manufacturing enterprises and supply chain initiatives must yield greater improvements than ever before. As indicated by the outcomes of recent business reports [5], large enterprises have yet exhausted most of the efficiencies available within their existing supply chain, so that further gains require structural changes that streamline the flow of supply and eliminate product and portfolio complexity that do not provide or protect value. These changes call for a dynamic and holistic approach that takes into consideration all aspects of the entire supply chain from a systems view [6].

An increasingly popular approach for enterprises striving to cope with the challenges of today's rapid changing and demanding environment has been the concept of "upgrading" their supply chains to Dynamic Manufacturing Networks (DMNs). The DMN concept evolves and particularizes the notion of virtual organizations [7] in the manufacturing sector, as it is a dynamic alliance of manufacturing entities collaborating for gaining mutual benefits [8-10]. Compared to a virtual organization however, a $\mathrm{DMN}$ is a real formation, though with loose ends and a quite flexible structure, which includes geographically dispersed OEMs and a pool of potential suppliers of various tiers. For an enterprise, participating in (or forming) a DMN can be considered as a systematic way for cultivating extended co-operation with other members of its supply chain, and calls for modifications in its modus operandi, while it necessitates the network's dynamic management [11-13], so as to enable real-time communication and active collaboration among the different network nodes.

This new modus operandi offers the enterprise a number of important benefits in the directions of enhancing manufacturing capacity and operational procedures, enlarging market share and improving viability and profits, but is also associated with a series of risks -the most important being related with information security and trustwhich have to be identified and mitigated. In this context, this paper aims to present benefits and risks that accrue from the formation of DMNs under the prism of the end-to-end DMN management methodology, developed within the context of the IMAGINE FP7 project. The remaining of this paper is thus structured as follows: Section 2 introduces the concept of DMNs in IMAGINE, along with the key drivers for their establishment and outlines the respective DMN management methodology. Section 3 exposes the anticipated DMN benefits identified, while Section 4 provides insight on the associated risks and the respective mitigation strategies. Finally, Section 5 summarizes the ideas presented and concludes the work. 


\section{DMN Concept, Business Incentives and IMAGINE Methodology}

The main idea behind DMNs is to achieve market differentiation through focusing on the core competencies and obtaining all other activities from outside, i.e. from other DMN members. The prospects of improving competitiveness, productivity and quality, enhancing efficiency and responsiveness to market demands, and exploring possibilities to lower overheads and costs are considered [14-15] as the most important driving forces for an enterprise to overcome its traditional operation and adopt a collaborative way of thinking and dealing with suppliers and partners, and are at the same time the benefits anticipated regardless of the scheme or scope of the DMN.

The term Dynamic Manufacturing Network denotes a permanent or temporal coalition, comprising production systems of geographically dispersed SMEs and/or OEMs that collaborate in a shared value-chain to conduct joint manufacturing [8]. Each member of the network produces one or more product components that can be assembled into final service-enhanced products under the control of a joint production schedule. Production schedules are monitored collectively to accomplish a shared manufacturing goal, while products are composed, (re-) configured and transformed on demand through dynamic and usually ad-hoc inter-organisational collaborations that can cope with evolving requirements and emergent behaviour.

From an operational point of view, this complex context of collaborations and interactions among enterprises and their suppliers, partners and customers is coordinated by a sophisticated IT platform and the respective DMN end-to-end management methodology [8]. The former revolves around the DMN lifecycle - comprising the DMN configuration, design, and monitoring and management phases - and is based on a Blueprint Model which gathers, consolidates and integrates manufacturing data and processes in order to develop actionable insights that help manage enterprise resources, product life cycles, supply chains, partner relationships, operational planning, manufacturing process execution, compliance regulations and safety issues for the DMN lifecycle, and thereby maximise the performance of participating enterprises. This model is a declarative meta-model that aggregates and modularises production, manufacturing operations and logistics information, distilled from Manufacturing Integration Standards, such as the ISA-88 and ISA-95 and the Open Applications Group Integration Specification (OAGIS), reference models such as the Supply Chain Operations Model (SCOR), and the Business-to-Manufacturing-Markup-Language (B2MML), and consists of four interrelated blueprints supporting information sharing, collaboration, enterprise-wide visibility and interoperability as follows:

- the Partner Blueprint, which provides business and technical information to facilitate partners' selection by a specific contractor,

- the Product Blueprint, containing all components necessary, such as machines, tools, personnel skills, materials, other equipment, for producing a product, as well as other entities necessary for the manufacturing work,

- the Quality Assurance Blueprint, used to capture metrics for operations analytics and associate these with the end-to-end manufacturing processes, and 
- the end-to-end Process Blueprint, which ties together the many discrete processes associated with all aspects of product development while providing the ability to adapt to changing conditions and environments.

The idea of the DMN, as defined in the IMAGINE project along with the concept and applicability of the DMN management methodology and Blueprint Model are the keys for materialising a series of anticipated DMN benefits, which are presented in Section 3, and mitigating the associated risks, exposed in Section 4 of this paper.

\section{Expected DMN Benefits}

Every DMN, regardless of its size and formation, has the same closely defined mission which is to enhance the entire value creation process of products and services and consequently to create extra profit and other benefits for all DMN members. In the context of the IMAGINE methodology, the expected DMN benefits can be classified in three categories, namely Time savings, Cost reduction and Enhancement of operations: Time savings are mainly associated with the time-to-market reduction, the optimized design of end products and individual components, collaborative product development, the network-optimized production planning and scheduling, the fast selection of suppliers for each project/product and the corresponding rapid network set-up, the instant reconfiguration of the suppliers' network, the automated communication and data exchange with suppliers/clients and partners, as well as the increased visibility and access speed to information and network/manufacturing data. On the other hand, cost savings may include the cost-optimized selection of suppliers, the reduction of inventory costs, the cost-optimized management of resources, as well as the decrease of marketing expenses. The last category of benefits, concerned with operations' enhancement includes these kinds of gains that are associated with improvements in the way that each individual enterprise and consequently the whole network operate, and can be indirectly linked either to time/cost reductions or to profitability rise for the whole network. This type of benefits in fact enumerates: a clear focus on core competences, product/services co-creation, cost/risk sharing with collaborating partners, real-time monitoring of product development and manufacturing operations, reduction of design and production flaws, optimal selection of suppliers and collaborators, improved quality throughout the complete product lifecycle, know-how exchange, access to new customers/markets, and diverse enterprise IT systems' integration for better, holistic and more efficient production.

Despite the above-mentioned long list of benefits, the decision of joining a DMN is still an important one for any enterprise, since it is related to many changes not only to the way the enterprise collaborates with the external environment, but also to the way that almost all the internal processes are being performed. This is why such a decision should always be based on real estimations of the expected benefits, taking into consideration good practices and success results achieved in previous collaboration cases, as specified through an extensive literature review:

As far as cost savings are concerned, research [16-17] shows that in a typical manufacturing sector like automotive, amazingly only $30 \%$ of the cost of the final product 
has to do with "value activities". The other $70 \%$ are the costs and overheads of running a major manufacturer in its current form. The scope for cost savings through collaborating in a DMN is therefore huge.

Previous experience on networked manufacturing as presented in several studies proves moreover that if manufacturing networks run properly they can generate up to $30 \%$ additional profit per member after the initial settling in period [17-18]. As seen in Table 1, this has to do with an estimated reduction of up to $25 \%$ concerning total manufacturing and operational costs, as well as a maximum of $20 \%$ reduction concerning costs, incurred due to poor quality issues. Additionally, increased profitability is also linked with the expected rise of productivity in a well-established DMN that can reach up to $30 \%$, according to cases examined in past studies [16]. Another important fact is that not only profits grow higher but also at the same time the financial exposure of partners may be decreased by $25 \%$. In fact, the overall reduction of required investments by the DMN members, whether the former regard IT infrastructure, knowledge or machinery, is estimated at a maximum of $20 \%$ [19].

Furthermore, very good results are expected, by joining a DMN, on the product development operations. Previous applications of collaborative product development processes like those in DMNs have proved that a reduction of lead-time and cost up to $30 \%$ and $50 \%$ respectively are realistic goals which can be achieved [20].

Finally, a carefully established and well-managed DMN can lead to a very efficient operation of all of its members. This is proved not only by the financial results, previously presented, but also by the improvement on the values of several metrics related to the operation of each individual enterprise and of the supply chain as a whole.

Table 1. Expected Benefits following a DMN formation

\begin{tabular}{lc}
\hline \multicolumn{1}{c}{ Metric } & Improvement up to \\
\hline Total Profitability & $\Uparrow 30 \%$ \\
Total operational \& manufacturing cost & $\Downarrow 25 \%$ \\
Cost due to quality issues & $\Downarrow 20 \%$ \\
Total productivity & $\Uparrow 30 \%$ \\
Financial exposure of partners & $\Downarrow 25 \%$ \\
Required investments by partners & $\Downarrow 20 \%$ \\
Product development lead time & $\Downarrow 30 \%$ \\
Product development cost & $\Downarrow 50 \%$ \\
Time for contractual formalization & $\Downarrow 50 \%$ \\
Time-to-market & $\Downarrow 25 \%$ \\
Manufacturing lead time & $\Downarrow 20 \%$ \\
Co-operation processes efficiency & $\Uparrow 30 \%$ \\
Product cycle times & $\Downarrow 50 \%$ \\
Life cycle costs & $\Downarrow 30 \%$ \\
Maintenance costs & $\Downarrow 30 \%$ \\
\hline
\end{tabular}


According to the literature on virtual enterprises and manufacturing networks the following achievements can be expected: reduction of time required for co-operation contractual formalization up to $50 \%$ [21], reduction of time-to-market up to $25 \%$ [21], [22], reduction of lead time up to $20 \%$ [21], [23], improved efficiency of co-operation processes (manufacturing network design, re-configuration and re-engineering) up to $30 \%$ [21], decrease of product cycle times up to $50 \%$ [18], of life cycle costs up to $30 \%$ [22], and of maintenance costs up to $30 \%$ [18].

It has to be noted that the figures presented in this paragraph are mostly based on specific examples/cases analyzed in the literature and cannot be considered as reference values for all cases. However, they provide a direction with regard to the objectives that should be set and expected when establishing a Dynamic Manufacturing Network and a good starting point for quantifying the above-mentioned anticipated DMN benefits, which are to be assessed along the course of the IMAGINE project.

\section{Potential DMN Risks}

Inarguably, the introduction of any new innovation does not come without any risk for possible adopters. According to Hallikas et al. [24], functions that generate the possibility of beneficial effects or profit often include risks. The same applies for the idea of walking away from typical, long operating models of traditional supply chains and moving to new models of virtual factories and the DMN concept in particular. The risks that may be encountered in a DMN are in fact associated with:

Information Security and Trust. Information leaks due to unwanted and malicious attacks, and disclosure of corporate practices and other critical or strategic importance data can prove to be very harmful for an enterprise, and can be mitigated by applying efficient security and efficient mechanisms, that impede unauthorized access and define different access rights for different partners, as well by signing contractual agreements with special clauses on information confidentiality.

Poor Configuration, Design and Management of the Network. This makes up a risk which may come up as a result of the provision of non-valid, deficient or even outdated information for carrying out partner searches and negotiations in the first place, as well as for coordinating the complex grid of multiple and diverse actors, functions, processes and flows of information involved thereafter. This risk may prove to be fatal even for the network's survival and can be addressed by granting dynamic, and therefore accurate information on the actual manufacturing and delivery capacity of each DMN member, as well as global visibility across the whole network so as to constantly fine tune its performance.

DMN dissolution when key partner drops out of the network. Withdrawal of a key supplier/manufacturer could jeopardize the success of a project, resulting even in the network's dissolution. Thus, it should be foreseen as a risk in the contracts signed upon the establishment of the DMN, so as to legally bind DMN members not to be able to waive their DMN responsibilities and obligations at will.

Transition issues related to resistance to change, modifications to procedures and IT systems. The transition from an isolated to a collaborative manufacturing model is 
not easy and may be accompanied by modifications in the procedures followed and the systems used as well as the employees' resistance. This risk is addressed by introducing a set of adapters that interconnect the IT systems of all DMN members to the DMN platform, and facilitating the unhampered exchange of information, enabling thereby smooth transition for both processes and people.

Competitive threats after a partner's withdrawal or the dissolution of the DMN. The risk of important R\&D knowledge misuse for gaining competitive advantage over former collaborators, in case a member exits the DMN or the former is dissolved, can be mitigated by signing legal agreements that explicitly define the use and exploitation of intellectual property and knowledge generated during the operation of the DMN.

Loss of DMN/ Partners' Reputation. A partner's inability to deliver as planned may affect the operation and damage the reputation of the overall DMN structure. Such a risk is to be mitigated pro-actively by allowing selection of the most appropriate partners as well as early detection of any deviation in the production plan, and triggering the network's reconfiguration with zero or minimal damage to the DMN reputation.

\section{$5 \quad$ Concluding Remarks}

The identification and analysis of the associated benefits and risks is the first step for identifying key factors that could be utilized in order to attract organizations and enterprises into embracing the vision of DMNs. In this context, and as a concluding remark, attention should be drawn to the fact that in most cases the drivers for setting up or for participating in a DMN are practically a mixture of several of the benefits identified, as well as to the observation that both the benefits and risks specified may have a different impact on DMN enterprises with different goals and expectations. This is something that should be taken into account when forming the DMN and setting the rules and norms for managing and operating it efficiently.

Acknowledgements. The research leading to these results has been supported by the EC $7^{\text {th }}$ Framework Programme under the project "IMAGINE - Innovative end-to-end management of Dynamic Manufacturing Networks" Grant Agreement No. 285132, (http://www.imagine-futurefactory.eu).

\section{References}

1. Shi, Y., Gregory, M.: International Manufacturing Networks - to develop global competitive capabilities. Journal of Operations Management 16, 195-214 (1998)

2. Powell, T.C.: Total Quality Management as Competitive Advantage: A Review and Empirical Study. Strategic Management Journal 16, 15-37 (1995)

3. Davenport, T.: Putting the Enterprise into the Enterprise System. Harvard Business Review, 121-131 (1998)

4. Yoon, S.C., Makatsoris, H.C., Richards, H.D. (eds.): Evolution of Supply Chain Management: Symbiosis of Adaptive Value Networks and ICT. Springer (2004) 
5. Payne, T.: Supply Chain Functional Excellence Key Initiative Overview. Gartner Inc. (2012)

6. Shi, Y.: A Roadmap of Manufacturing System Evolution-From Product Competitive Advantage towards Collaborative Value Creation. In: Yoon, S.C., Makatsoris, H.C., Richards, H.D. (eds.) Handbook Evolution of Supply Chain Management, pp. 341-365. Springer (2004)

7. Katzy, B.R., Schuh, G.: The Virtual Enterprise. In: Molina, A., Sánchez, J.M., Kusiak, A. (eds.) Handbook of Life Cycle Engineering: Concepts, Methods and Tools, pp. 59-92. Springer (1999)

8. IMAGINE Project: Innovative End-to-end Management of Dynamic Manufacturing Networks. Description of Work (2011), http: / /www . imagine-futurefactory . eu

9. Viswanadham, N.: Partner Selection and Synchronized Planning in Dynamic Manufacturing Networks. IEEE Transactions on Robotics and Automation 19(1), 117-130 (2003)

10. Papakostas, N., Efthymiou, K., Georgoulias, K., Chryssolouris, G.: On the Configuration and Planning of Dynamic Manufacturing Networks. Logistics Research Journal, 1-7 (2012)

11. Accenture: Developing Dynamic and Efficient Operations for Profitable Growth - Research Findings from North American Manufacturers (2012)

12. Williams, G.P.: Dynamic Order Allocation for Make-to-order Manufacturing Networks: An Industrial Case Study of Optimization under Uncertainty. Massachusetts Institute of Technology (2011)

13. University of St. Gallen: Global Manufacturing Networks (2012)

14. Cunha, M.M., Putnik, G.: Agile Virtual Enterprises: Implementation and Management Support. Idea Group Inc. (IGI) (2006)

15. Cueni, T., Seiz, M.: Virtual Organizations - the next Economic Revolution? Swiss Federal Institute of Technology, Lausanne, EPFL (1999)

16. Chalmeta, R., Grangel, R.: Performance Measurement Systems for Virtual Enterprise Integration. Int. J. Computer Integrated Manufacturing 18(1), 73-84 (2005)

17. Thompson, K.: Achieve Supply Chain Agility through Virtual Enterprise Networks. Case Studies in Collaboration (2005), http: / / www . bioteams . com (retrieved January 04, 2012)

18. Landeg, B., Ash, S.: Implementation of Airbus Concurrent Engineering. In: 85th AGARD SMP Meeting on "Virtual Manufacturing", Aalborg (1997)

19. Thompson, K.: A kick-start plan for setting up a Virtual Enterprise Network in 6 weeks. Case Studies in Collaboration (2005), http: / / www . bioteams . com (retrieved January 04,2012 )

20. Karlsson, L., Löfstrand, M., Larsson, A., Törlind, P., Larsson, T., Elfström, B.O., Isaksson, O.: Information driven Collaborative Engineering: Enabling Functional Product Innovation. In: 3rd International Workshop on Challenges in Collaborative Engineering, CCE 2005, Sopron (2005)

21. Santoro, R., Conte, M.: Evaluation of Benefits and Advantages of the Virtual Enterprise approach adoption for Actual Business Cases. In: 8th International Conference on Concurrent Enterprising, Rome (2002)

22. Renton, W.J., Rudnick, F.C., Brown, R.G.: Virtual Manufacturing Technology Implementation at Boeing. In: 85th AGARD SMP Meeting on "Virtual Manufacturing", Aalborg (1997)

23. Kingsbury, A.: Use of Virtual Prototyping in Design and Manufacturing. In: 85th AGARD SMP Meeting on "Virtual Manufacturing", Aalborg (1997)

24. Hallikas, J., Karvonen, I., Pulkkinen, U., Virolainen, V.M., Tuominen, M.: Risk Management Processes in Supplier Networks. Int. J. Production Economics 90, 47-58 (2004) 